\title{
Use of Convalescent Plasma Therapy for COVID-19: A Scientometric Assessment of Global Publications during 2020-21
}

\author{
BM Gupta ${ }^{1, *}$, SM Dhawan², KK Mueen Ahmed ${ }^{3}$, Ghouse Modin Mamdapur ${ }^{4}$
}

\section{BM Gupta ${ }^{1, *}$, SM Dhawan², KK Mueen Ahmed ${ }^{3}$, Ghouse Modin Mamdapur ${ }^{4}$ \\ ${ }^{1}$ Formerly with CSIR-NISTADS, New Delhi, INDIA. \\ ${ }^{2}$ Formerly with CSIR-NPL, New Delhi, INDIA. \\ ${ }^{3}$ Phcog.Net, Bengaluru, Karnataka, INDIA. \\ ${ }^{4}$ Synthite Industries $(P) L t d$, Kolenchery, Kerala, INDIA.}

\author{
Correspondence \\ Dr. BM Gupta \\ Formerly with CSIR-NISTADS, New \\ Delhi-11012, INDIA \\ Mobile no: +91 9888378275 \\ Email: bmgupta1@gmail.com \\ History \\ - Submission Date: 01-02-2021; \\ - Revised Date: 27-02-2021; \\ - Accepted Date: 15-03-2021
}

DOI : 10.5530/ijmedph.2021.2.13

Article Available online

http://www.ijmedph.org/v11/i2

\section{Copyright}

(C) 2021 Phcog.Net. This is an openaccess article distributed under the terms of the Creative Commons Attribution 4.0 International license.

\begin{abstract}
The study evaluates the global research output (820 records) on "Use of Convalescent Plasma Therapy for COVID-19" on metrics with the aim to understand the current status of research at the global, national, institutional, and individual author level. The study is based on publications and citations data sourced from the Scopus database during 2020-21. The publications and citations data was statistically analyzed on various metrics such as document type, country of publication, collaboration patterns, author affiliation, journal name, and citation patterns. The USA, China and India lead the world ranking of 15 most productive countries in the subject. China, U.K. and Netherlands lead in the ranking of most cited countries. In addition, the study maps key productive institutions, key authors, key source journals, as well as most significant keywords in the subject to visually present their inter-relationships using Biblioshiny and VOSviewer software. This results and findings from the study describe the progress made by the world in this hot area of global interest.
\end{abstract}

Key words: Convalescent plasma, Serum therapy, Plasma therapy, COVID-19, Scientometric, Bibliometric.

\section{INTRODUCTION}

Since December 2019, a pneumonia outbreak associated with severe acute respiratory syndrome coronavirus 2 (SARS-CoV-2) had caused a worldwide epidemic. World Health Organization (WHO) named this virus as coronavirus disease 2019 (COVID-19). It spread rapidly worldwide with a high rate of transmission and substantial mortality. COVID-19 symptoms range from mild, self-limited respiratory disease to severe progressive pneumonia, multiple organ failure, and even death. WHO declared it as a pandemic on March 11, 2020. As of February 2021, a total 103,631,793 confirmed cases and 2251613 deaths had been reported in 223 countries. ${ }^{1}$

Considering that there has been no proven therapy in terms of effective vaccine (though it is now available) and specific antiviral medicine, it was necessary and urgent on the part of scientists and doctors to look for an alternative strategy or option for COVID-19 treatment, especially for the benefit of patients with sever symptoms. Ongoing research in this area has resulted a multiple studies on the use of convalescent plasma for COVID-19 to treat severely or critically ill COVID-19 patients, without unexpected or serious adverse events. ${ }^{2}$ Convalescent plasma (CP) therapy (or passive immunization or serum therapy), a classic adaptive immuneotherapy, was born from the intuition of Behring and Kisato in the late $19^{\text {th }}$ century. It was widely used for the treatment of bacterial infections until the discovery of antibiotics, as well as during the viral pandemics of the $20^{\text {th }}$ century and in the beginning of the $21^{\text {st }}$ century. It still has clinical applications (e.g., tetanus prevention). The use of convalescent plasma involves transfusing plasma collected from patients who have already recovered from an illness, in an attempt to transfer neutralizing antibodies and confer passive immunity. The potential efficacy of convalescent plasma was first described during the Spanish influenza pandemic of the early 1900s Since then, convalescent plasma has been used to treat a wide range of viral infections, including measles, parvovirus B19, H1N1, Ebola and some coronaviruses. Among the many coronaviruses that are only mildly pathogenic to humans, there are three that have caused notably severe clinical manifestations and have been treated with convalescent plasma: i) severe acute respiratory syndrome coronavirus (SARS-CoV), ii) Middle East respiratory syndrome coronavirus (MERS-CoV) and iii) severe acute respiratory infections (SAR) viruses. ${ }^{3}$ Virus neutralization by antibodies is the principle behind the functioning of plasma of patients recovered from SARS-CoV-2; high-titer-specific antibodies bind to SARS-CoV-2 neutralizing the viral particles, blocking access to cells, and activating potent effect or mechanisms, such as complement activation and phagocytosis. ${ }^{4}$

Recently, in 2017, the WHO Blood Regulators Network (BRN) published a position paper 
recommending convalescent plasma as the first-choice treatment to be tested in the absence of authorized drugs; however, this strategy has not been followed. In the current epidemic, the principle of passive immunization through convalescent plasma has been applied in several circumstances and particularly in patients with serious complications. Also, the FDA of USA has proposed plasma treatment in order to face the increasingly complex situation and manage patients with serious or immediately life-threatening COVID-19 disease. Several studies and clinical programs are still ongoing and more extensive studies are now in the pipeline to provide a robust evidence for or against the use of convalescent plasma. Worldwide there are over 60 clinical trials actively recruiting COVID-19 patients to study the effect of convalescent plasma. ${ }^{5}$ Given the ongoing trends in "Use of Convalescent Plasma Therapy for COVID-19" it is considered worthwhile that a bibliometric study be undertaken to understand and describe the current state of research in the subject based on global literature published till date.

\section{Literature Review}

Till date, quite a few studies have been undertaken to assess and describe the state of global research in COVID-19 literature using bibliometric methods. A review of such studies is described here. Zyoud and Al-Jabi ${ }^{6}$ performed a bibliometric analysis to track the current hotspots and identify future directions in COVID-19 (19,044 publications). Research studies related to COVID-19 were obtained from the Scopus database during the early stage of the outbreak. The data was analyzed by using well-established bibliometric indices such as document type, country, collaboration patterns, affiliation, journal name, and citation patterns. Biblioshiny and VOSviewer were used to map and determine hot topics in this field. The most discussed topics of research in COVID-19 include "clinical features studies", "pathological findings and therapeutic design", "care facilities preparation and infection control", and "maternal, perinatal and neonatal outcomes". Philip Shapira ${ }^{7}$ undertook a bibliometric study to analyze COVID-19 related scientific publications through to October of 2020 and described broad trends, fields, countries, and organizations in the subject. Two different databases were used for sourcing data: PubMed and the Web of Science. Yue Gong et al. ${ }^{8}$ analysed the global literature related to COVID-19 using bibliometric methods, citation analysis, and knowledge mapping methods. Studies reported temporal patterns, main countries affected, and core subjects. The status and trends in COVID-19 research were explored from January 2020 to March 2020 to reveal the conceptual knowledge map in SARS-CoV-2. The results provide a reference point for the current and future coronavirus research studies for policymaking worldwide. Lou, Tian, Niu, Kang, Lian, Zhang and Zhang' analysed the publications about COVID-19 to summarize the research hotspots and make a review, to provide a reference point for researchers in the world. The authors searched PubMed using the keywords "COVID-19" from inception to March 1, 2020. They identified and analyzed the data which included title, corresponding author, language, publication time, publication type, research focus. It is evident from this literature review that not even a single bibliometric study has appeared so far on the topic of 'application of convalescent plasma therapy to COVID-19 patients'. Given this context, it was decided to undertake a bibliometric study in the proposed subject.

\section{Objectives}

The purpose of this study is to analyze and evaluate the literature on "Use of Convalescent Plasma Therapy for COVID-19" on bibliometric indicators as a way to understand the status of global research in the subject. The data for the study was sourced from the Scopus database covering the period 2020-2021. The study attempt to describe the global research on a series of metrics such as (I) publication output count, type and source, (ii) annual growth trends, (iii) citation trends, (iv) identify key countries, organizations, individual authors, (v) highlight most significant keywords, most sought after subject areas of interest, (vi) research collaborative linkages, (vii) most preferred source journals, and (viii) characterize bibliographic features of highly cited papers on this topic.

\section{METHODOLOGY}

A well-defined search strategy was used to retrieve and download publications data from the Scopus database. The search for global literature published on "Use of Convalescent Plasma Therapy for COVID-19" was conducted on 21.1.2021 with no publication date limitations. Key search terms were clubbed into two sets: (i) "COVID 19" OR "2019 novel coronavirus" OR “coronavirus 2019” OR "coronavirus disease 2019" OR "2019-novel CoV” OR "2019 ncov" OR "covid 2019" OR “covid19” OR "corona virus 2019” OR "ncov-2019” OR “ncov2019” OR “nCoV 2019” OR “2019-ncov” OR “covid-19” OR "Severe acute respiratory syndrome coronavirus 2" OR "SARS-CoV-2" and (ii) "plasma therapy" or "Convalescent plasma". These two set of keywords were tagged to "Keyword" and "Article Title" tags as described below. The database search resulted 820 records as global output. All types of documents were included in the search output. The global output was subsequently analyzed for publication trends by author, affiliation, journal, country of publication, top-cited countries, topcited documents, country-wise research collaboration and by keywords. ((TITLE ("COVID 19" OR "2019 novel coronavirus" OR "coronavirus 2019” OR “coronavirus disease 2019” OR “2019-novel CoV” OR “2019 ncov" OR covid 2019 OR covid19 OR "corona virus 2019" OR ncov2019 OR ncov2019 OR "nCoV 2019” OR 2019-ncov OR covid-19 OR "Severe acute respiratory syndrome coronavirus 2" OR "SARS-CoV-2" ) OR (KEY ( "COVID 19" OR "2019 novel coronavirus" OR "coronavirus 2019” OR “coronavirus disease 2019” OR “2019-novel CoV” OR “2019 ncov” OR covid 2019 OR covid19 OR “corona virus 2019” OR ncov2019 OR ncov2019 OR “nCoV 2019” OR 2019-ncov OR covid-19 OR "Severe acute respiratory syndrome coronavirus 2" OR "SARS-CoV-2" ) and KEY (Plasma Therapy ${ }^{\star}$ or Convalescent plasma ))).

\section{ANALYSIS AND RESULTS}

The search on theme "Use of Convalescent Plasma Therapy for COVID-19" in Scopus database resulted in a total of $820(2020=790$; $2021=30$ ) publications. The global publications (820) received 10641 citations, averaging to 12.98 citations per paper. Of the 820 publications, $170(20.73 \%)$ resulted from research projects funded by $100+$ funding agencies, received 4316 citations, averaging to 25.39 citations per paper. The major funding agencies supporting research projects are: National Institute of Health, USA (39 publications), National Natural Science Foundation of China (31 papers), National Institute of Allergy and Infectious Diseases (11 papers), Canadian Institute of Health Research, National Cancer Institute, National Heart, Lung and Blood Institute, USA and National Key Research and Development Program of China (7 papers each), etc.. Of the total output, articles and reviews account for the largest publications share $(34.61 \%$ and $34.27 \%)$, followed by letters $(12.07 \%)$, notes $(6.83 \%)$ and the rest by others. English was the dominant publishing language (with 797 publications), followed by Chinese (6), Russian (5), French (3), Czech, Hungarian and Spanish (2 each) and 3 other languages with 1 each.

\section{Top 15 Most Productive Countries}

In all, 90 countries participated in global research on "Use of Convalescent Plasma Therapy for COVID-19" but the distribution of productivity by country of origin is highly skewed. For instance, 56 countries contributed 1-5 papers each, 15 countries 6-10 papers each, 8 countries 11-20 papers 
each, 6 countries 21-50 papers each, 2 countries 51-100 papers each and 3 countries 104-286 papers each. The USA, China and India lead in global ranking with most publication share of $34.88 \%, 15.98 \%$ and $12.68 \%$ respectively, followed by 12 other countries which together accounted for a $36.46 \%$ global share. In terms of research citations performance only three countries - China (39.78 and 3.06), U.K. (23.64 and 1.82) and Netherlands (20.69 and 1.59) performed above the world average (14.33 CPP and 1.10 RCI) (Table 1).

A networks map of top 15 most productive countries, generated using VOSviewer software tool. Figure 1, visually presents their comparative productivity and their interrelations for collaborative research in the subject. The United States dominates in research productivity as well as in international collaboration, followed by China and India. The size of the circle of a country is proportional to its productivity. The thickness of links between countries represents the strength of their collaborative contributions to the research topic. Network visualization of countries is grouped into four clusters. Cluster 1 and 2, in red and green colour, and they represent 6 countries each - (the United States, China, India, Canada, Saudi Arabia and South Africa) and (Italy, the United Kingdom, France, Turkey, Germany and Netherlands), followed by clusters 3 illustrated in blue colour with 2 countries (Iran and Australia) and the last cluster in yellow colour comprises 1 country (Brazil).

\section{Collaborative Linkages among Top 15 Countries}

The country-wise collaboration links between countries are depicted in Figure 2. The size of the node is proportional to the collaborative activity of the country. The biblioshiny app web interface divides the most productive 15 countries grouped into 3 clusters. Cluster 1 orange colour represents the USA, India, and China are the biggest nodes and followed by the United Kingdom and Italy belong to the blue colour cluster 2 and Turkey belong to the red cluster 3 respectively. A line between the two countries indicates their collaborative linkages in research. The thickness of lines connecting the countries indicates the degree of their co-authorship in publications. When the two countries connected by one line, it indicates that they collaborated to publish a single paper. The USA, U.K. and Italy collaborated with 13-14 countries and top the list with most collaborative linkages (131, 78 and 48). The bottom three countries (Turkey, France and Iran) collaborated with 6-11 countries but rank at the bottom with least number of collaborative linkages $(6,22$ and 26). Of the collaborative linkages at the country-country level, USAChina, registered the highest number of collaborative linkages (20), followed by USA-U.K (16 linkages), USA-India (15 linkages), U.S.ACanada (13 linkages), USA-Italy (12 linkages), USA-Iran, USA-Brazil and Italy-U.K.(9 linkages each), USA-Saudi Arabia, USA-Australia, USA-Netherlands, China-Canada, India-Saudi Arabia, U.K.-Canada and U.K.-Australia (8 linkages each), etc. (Table 2).

\section{Subject-Wise Distribution of Research Output}

The Scopus database organized global research output on "Use of Convalescent Plasma Therapy for COVID-19" under four broad disciplines (Table 3 ). Medicine accounts for a $81.83 \%$ share of publications, followed by Immunology and Microbiology (18.41\%), Pharmacology, Toxicology and Pharmaceutics (14.39\%) and Biochemistry, Genetics and Molecular Biology (16.71\%). In terms of discipline-wise research performance on citations, Immunology and Microbiology registered the

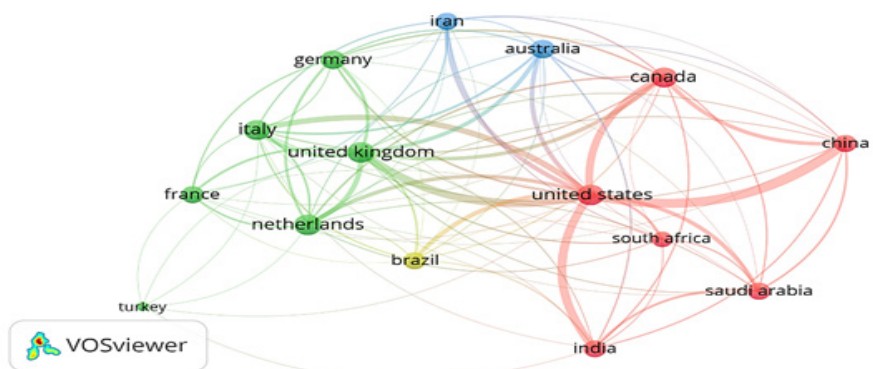

Figure 1: Networks Map of 15 Most Productive Countries.

Table 1:Top 15 Most Productive Countries Global Publication Output and Share in Research on “Use of Convalescent Plasma Therapy for COVID-19."

\begin{tabular}{|c|c|c|c|c|c|c|c|c|c|c|}
\hline S.No & Name of the Country & TP & TC & CPP & $\% \mathrm{TP}$ & $\mathrm{HI}$ & ICP & \%ICP & $\mathrm{RCl}$ & $\mathrm{TCL}$ \\
\hline 1 & USA & 286 & 2813 & 9.84 & 34.88 & 26 & 96 & 33.57 & 0.76 & 208 \\
\hline 2 & China & 131 & 5211 & 39.78 & 15.98 & 27 & 38 & 29.01 & 3.06 & 88 \\
\hline 3 & India & 104 & 1046 & 10.06 & 12.68 & 12 & 32 & 30.77 & 0.77 & 79 \\
\hline 4 & Italy & 57 & 349 & 6.12 & 6.95 & 11 & 26 & 45.61 & 0.47 & 78 \\
\hline 5 & U.K. & 53 & 1253 & 23.64 & 6.46 & 11 & 40 & 75.47 & 1.82 & 135 \\
\hline 6 & Canada & 39 & 223 & 5.72 & 4.76 & 8 & 28 & 71.79 & 0.44 & 79 \\
\hline 7 & Iran & 35 & 281 & 8.03 & 4.27 & 7 & 18 & 51.43 & 0.62 & 46 \\
\hline 8 & Saudi Arabia & 29 & 153 & 5.28 & 3.54 & 6 & 20 & 68.97 & 0.41 & 57 \\
\hline 9 & Australia & 25 & 352 & 14.08 & 3.05 & 6 & 19 & 76.00 & 1.08 & 62 \\
\hline 10 & France & 25 & 256 & 10.24 & 3.05 & 8 & 13 & 52.00 & 0.79 & 47 \\
\hline 11 & Turkey & 24 & 68 & 2.83 & 2.93 & 4 & 5 & 20.83 & 0.22 & 12 \\
\hline 12 & Brazil & 18 & 56 & 3.11 & 2.20 & 5 & 11 & 61.11 & 0.24 & 51 \\
\hline 13 & Germany & 18 & 97 & 5.39 & 2.20 & 4 & 13 & 72.22 & 0.42 & 50 \\
\hline 14 & Netherlands & 16 & 331 & 20.69 & 1.95 & 6 & 15 & 93.75 & 1.59 & 77 \\
\hline \multirow[t]{3}{*}{15} & South Africa & 15 & 49 & 3.27 & 1.83 & 3 & 9 & 60.00 & 0.25 & 43 \\
\hline & Total of 15 countries & 875 & 12538 & 14.33 & 106.71 & 9.6 & 383 & 43.77 & 1.10 & 1112 \\
\hline & Global total & 820 & 10641 & 12.98 & 100.00 & & & & & \\
\hline
\end{tabular}

TP - Total Publications, TC - Total Citations, CPP - Citations per Paper, HI - Hersh Index, ICP - International Collaborative Publications, RCI - Relative Citations Index, TCL - Total Collaborative Linkages 
highest rate of citations per paper (19.42 CPP) and it was the least for Pharmacology, Toxicology and Pharmaceutics (4.50 CPP) (Table 3).

\section{Sub-Field-Wise Distribution of Global Output.}

On further classification of global output on "Use of Convalescent Plasma Therapy for COVID-19" under topical areas, it was found that 'clinical studies' accounted for most share (47.44\%) of publications, followed by 'treatment outcome' (12.20\%), 'complications' (12.07\%), pathophysiology (8.29\%), epidemiology (5.37\%) and genetics (5.0\%). In terms research performance on citations, 'genetics' sub-area registered the highest citations per paper 43.71 citations per paper, followed by pathophysiology (24.22), treatment outcome (21.60), clinical studies (17.39), complications (14.89) and epidemiology (10.43) (Table 4).

\section{Significant Keywords}

The keyword co-occurrence in research publications serves as a secondary support to get an insight into main topics and research trends in the "use of convalescent plasma therapy for COVID-19". Figure 3 $(A \& B)$ were generated through VOSviewer software and Biblioshiny app web interface application. Figure $3 \mathrm{~A}$ is a networks map of keyword cooccurrences at a glance. Figure 3B presents textual data about keywords in a simple way. The keywords are listed in Table 5 in the decreasing order of the frequency of their occurrence in the literature. The most significant keywords such as Coronavirus Disease, Convalescent Plasma, Severe Acute Respiratory Syndrome Coronavirus 2 (SARS-CoV-2), Pandemic, Coronavirus Infection, Viral Pneumonia appear in circles. The circle size and font size in Figure 3A is proportional to the frequency of occurrence of a keyword. The links between the keywords show that these keywords co-occur in the literature.

On classifying global research publications on the theme "Use of Convalescent Plasma Therapy for COVID-19" under different patient

Table 3: Subject-Wise Breakup of Global Publications on “Use of Convalescent Plasma Therapy for COVID-19" Research.

\begin{tabular}{cccccc} 
S.No. & Subject & TP & \%TP & TC & CPP \\
\hline 1 & Medicine & 671 & 81.83 & 9094 & 13.55 \\
2 & Immunology and Microbiology & 151 & 18.41 & 2933 & 19.42 \\
3 & Pharmacology, Toxicology and & 118 & 14.39 & 531 & 4.50 \\
& $\begin{array}{c}\text { Pharmaceutics } \\
4\end{array}$ & & & & \\
& $\begin{array}{c}\text { Biochemistry, Genetics and } \\
\text { Molecular Biology }\end{array}$ & 137 & 16.71 & 1175 & 8.58 \\
& Global Total & 820 & 100.00 & 10641 & 12.98
\end{tabular}

${ }^{*} \mathrm{TP}=$ Total publications; $\mathrm{TC}=$ Total citations; $\mathrm{CPP}=$ Citations per paper

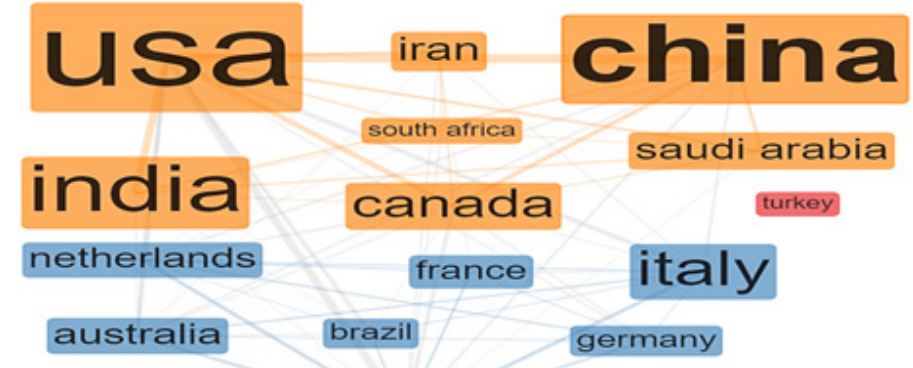

united kingdom

Figure 2: Research Collaboration Networks Map of Top 15 Countries.
A.

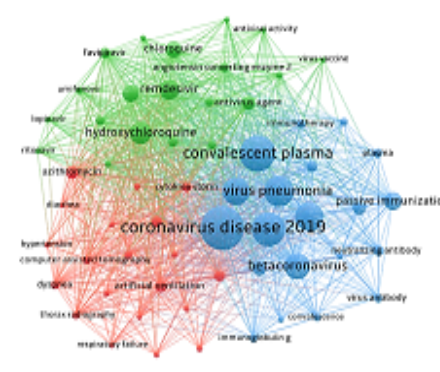

B.

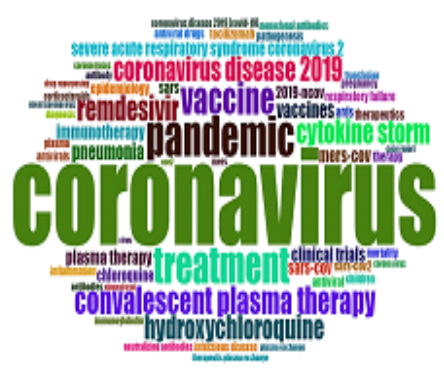

Figure 3: (A) The top 60 Keyword co-occurrence and (B) Word Cloud Keyword co-occurrence.

Table 2: Collaborative Linkages among top 15 countries in Research on “Use of Convalescent Plasma Therapy for COVID-19."

\begin{tabular}{|c|c|c|c|}
\hline S.No & Country Name & Number of Collaborative linkages with other countries & $\mathrm{TCL}(\mathrm{NOC})$ \\
\hline 1 & USA & $2(20), 3(15), 4(12), 5(16), 6(13), 7(9), 8(8), 9(8), 10(1), 11(1), 12(9), 13(4), 14(8), 15(5)$ & $131(14)$ \\
\hline 2 & China & $1(20), 3(3), 4(2), 5(2), 6(8), 8(4), 9(2), 10(1), 13(1), 14(2)$ & $45(10)$ \\
\hline 3 & India & 1(15), 2(3), 4(1), 5(2), 6(3), 8(8), 9(3)11(1), 12(2), 14(1), 15(2) & $41(11)$ \\
\hline 4 & Italy & 1(12), 2(2), 3(1), 5(9), 6(3), 7(3), 8(1), 9(5), 10(2), 11(1), 12(3), 13(2), 14(4) & $48(13)$ \\
\hline 5 & U.K. & 1(16), 2(2), 3(2), 4(9), 6(8), 7(3), 8(2), 9(8), 10(5), 11(1), 12(4), 13(6), 14(9), 15(3) & $78(14)$ \\
\hline 6 & Canada & 1(13), 2(8), 3(3), 4(3), 5(8), 7(3), 8(3), 9(4), 10(1), 13(4), 15(1) & $51(11)$ \\
\hline 7 & Iran & 1(9), 2(1), 4(3), 5(3), 6(3), 9(2), 10(2), 12(1), 13(1), 14(1) & $26(10)$ \\
\hline 8 & Saudi Arabia & $1(8), 2(4), 3(5), 4(1), 5(2), 6(3), 9(1), 10(1), 13(1), 14(2), 15(3)$ & $31(11)$ \\
\hline 9 & Australia & 1(8), 2(2), 3(3), 4(5), 5(8), 6(4), 7(2), 8(1), 12(2), 13(3), 14(2), 15(1) & $40(12)$ \\
\hline 10 & France & 1(1), 2(1), 4(2), 5(5), 6(1), 7(2), 8(1), 11(1), 12(1), 13(3), 14(4) & $22(11)$ \\
\hline 11 & Turkey & $1(1), 3(1), 4(1), 5(1), 10(1), 14(1)$ & $6(6)$ \\
\hline 12 & Brazil & 1(9), 3(2), 4(3), 5(4), 6(2), 7(1), 9(2), 10(1), 13(1), 14(1), 15(1) & $27(11)$ \\
\hline 13 & Germany & $1(4), 2(1), 4(2), 5(6), 6(4), 8(1), 9(3), 10(1), 12(1), 14(5)$ & $28(10)$ \\
\hline 14 & Netherlands & 1(8), 2(2), 3(1), 4(4), 5(9), 6(4), 8(2), 9(2), 10(4), 11(1), 12(2), 13(5), 15(2) & $46(13)$ \\
\hline 15 & South Africa & $1(5), 3(2), 5(3), 6(2), 8(1), 12(1), 13(1), 14(2)$ & $17(8)$ \\
\hline
\end{tabular}

$\mathrm{TCL}=$ Total collaborative linkages; NOC=Number of countries 
Table 4: Sub-field wise break-up of publications on "Use of Convalescent Plasma Therapy for COVID-19" Research.

$\begin{array}{cccccc}\text { S.No } & \text { Sub-field } & \text { TP } & \text { TC } & \text { CPP } & \text { \% TP } \\ 1 & \text { Clinical Studies } & 389 & 6763 & 17.39 & 47.44 \\ 2 & \text { Epidemiology } & 44 & 459 & 10.43 & 5.37 \\ 3 & \text { Genetics } & 41 & 1792 & 43.71 & 5.00 \\ 4 & \text { Pathophysiology } & 68 & 1647 & 24.22 & 8.29 \\ 5 & \text { Treatment Outcome } & 100 & 2160 & 21.60 & 12.20 \\ 6 & \text { Complications } & 99 & 1474 & 14.89 & 12.07 \\ & & 820 & 10641 & 12.98 & \end{array}$

${ }^{*} \mathrm{TP}=$ Total publications; $\mathrm{TC}=$ Total citations; $\mathrm{CPP}=$ Citations per paper population groups, it was found that studies on adults patient group account for the largest publication share $(22.56 \%)$, followed by middle aged (18.85\%), aged (15.49\%), child (3.66\%) and adolescents (3.05\%). In terms of research performance measured on citations, aged patients group studies registered the highest citations per paper (25.57), followed by middle aged group (24.22), adult group (19.97), adolescents (19.08) and child (15.10) (Table 6).

\section{Most Productive Global Organizations}

In all, 457 organizations were found to have participated unevenly in global research on "Use of Convalescent Plasma Therapy in COVID-19 Patents". The productivity of top 25 most productive organizations varied from 8 to 21 publications per organization whereas the global average productivity of all organizations was just 1.79 per organization. Secondly, the organization-wise distribution of global research output is highly skewed. For instance, the top 25 organizations together contributed

Table 5: Significant Keywords Appearing in Global Publications in Research on “Use of Convalescent Plasma Therapy for COVID-19."

\begin{tabular}{|c|c|c|c|c|c|}
\hline S.No & Name of the Keyword & Frequency & S.No & Name of the Keyword & Frequency \\
\hline 1 & Coronavirus Disease 2019 & 706 & 31 & Virus Transmission & 94 \\
\hline 2 & Convalescent Plasma & 546 & 32 & Immunotherapy & 87 \\
\hline 3 & $\begin{array}{l}\text { Severe Acute Respiratory Syndrome } \\
\text { Coronavirus 2(SARS-CoV-2) }\end{array}$ & 526 & 33 & Computer Assisted Tomography & 86 \\
\hline 4 & Pandemic & 507 & 34 & Immunoglobin $\mathrm{G}$ & 82 \\
\hline 5 & Coronavirus Infection & 411 & 35 & Methylprednisolone & 81 \\
\hline 6 & Virus Pneumonia & 405 & 36 & Thorax Radiography & 80 \\
\hline 7 & Beta coronavirus & 362 & 37 & Randomized Control Trials & 87 \\
\hline 8 & Passive Immunization & 324 & 38 & Umifenovir & 77 \\
\hline 9 & Hydrooxychoroquine & 298 & 39 & Convalescence & 74 \\
\hline 10 & Remdesivir & 268 & 40 & Virus Replication & 69 \\
\hline 11 & Lopinavir Plus Ritonavir & 209 & 41 & Dexamethasone & 68 \\
\hline 12 & Choloroquine & 194 & 42 & Extracorporeal Oxygenation & 65 \\
\hline 13 & Antivirus Agents & 167 & 43 & Oxygen Therapy & 65 \\
\hline 14 & Immunology & 160 & 44 & Oseltamivir & 64 \\
\hline 15 & Plasma Transfusion & 160 & 45 & Plasma Exchange & 64 \\
\hline 16 & Azithromycin & 156 & 46 & Lopainavir & 58 \\
\hline 17 & Artificial Ventilation & 135 & 47 & Respiratory Failure & 58 \\
\hline 18 & Neutralizing antibody & 124 & 48 & Convalescent Plasma Therapy & 57 \\
\hline 19 & Favipiravir & 123 & 49 & Anti-Viral Activity & 56 \\
\hline 20 & Adult Respiratory Distress Syndrome & 120 & 50 & $\begin{array}{l}\text { Enzyme Linked Immunosorben } \\
\text { Assay }\end{array}$ & 56 \\
\hline 21 & Immunoglobulin & 119 & 51 & Ritonavir & 56 \\
\hline 22 & Virology & 116 & 52 & Multiple Organ Failure & 55 \\
\hline 23 & Corticosteroid & 114 & 53 & Hypertension & 53 \\
\hline 24 & Ribavirin & 106 & 54 & Throat Culture & 53 \\
\hline 25 & Cytokino Storm & 99 & 55 & Virus Vaccine & 53 \\
\hline 26 & Dyspnea & 98 & 56 & Lymphocytopenia & 52 \\
\hline 27 & Plasma & 98 & 57 & $\begin{array}{c}\text { Reverse Transcription Polymerase } \\
\text { Chain Reaction }\end{array}$ & 52 \\
\hline 28 & Angiotensing Converting Enzyme 2 & 97 & 58 & SARS-CoV-2 Vaccine & 52 \\
\hline 29 & Virus Antibody & 96 & 59 & Sarilumab & 52 \\
\hline 30 & Anti-Viral Therapy & 95 & 60 & Diarrhea & 51 \\
\hline
\end{tabular}


a 34.15\% (280) global publications share. Besides, 404 out of 457 organizations published 1-5 papers each, 46 organizations 6-10 papers each and 7 organizations 11-21 papers each. Of the 25 organizations, 9 were from the USA, 5 from China, 2 each from Canada, Iran and South Africa and 1 each from France, India, Saudi Arabia, Singapore and South Africa. Table 6: Distribution by Patient Population Age Groups in “Use of
Convalescent Plasma Therapy for COVID-19."

$\begin{array}{cccccc}\text { S.No } & \text { Population Group } & \text { TP } & \text { TC } & \text { CPP } & \text { \%TP } \\ 1 & \text { Adults } & 185 & 3695 & 19.97 & 22.56 \\ 2 & \text { Middle Aged } & 130 & 3149 & 24.22 & 15.85 \\ 3 & \text { Aged } & 127 & 3248 & 25.57 & 15.49 \\ 4 & \text { Child } & 30 & 453 & 15.10 & 3.66 \\ 5 & \text { Adolescents } & 25 & 477 & 19.08 & 3.05 \\ & \text { Global output } & 820 & 10641 & 12.98 & 100.00\end{array}$

${ }^{*} \mathrm{TP}=$ Total publications; $\mathrm{TC}=$ Total citations; $\mathrm{CPP}=$ Citations per paper
The publications profile of top 25 most productive organizations is shown in Table 7. Six (shaded in green colour) out of top 25 organizations contributed above the group-25 average productivity (11.2), and four (shaded in yellow colour) registered their research performance (measured on metrics such as 'citations per paper' and 'relative citation index') above the group-25 average (28.45 CPP and 2.19 RCI).

\section{Collaboration among top 25 organizations}

The research collaboration network map (Figure 4) depicts top 25 organizations in 6 clusters. The Biblioshiny app was used to analyse the distribution and collaboration of top institutes in the field of "Use of Convalescent Plasma Therapy for COVID-19". The box size and font size of each node is proportional to its publication output in the field. The bigger the font and box size of the node, the higher its output. The top five institutes with most publications output include Icahn School of Medicine at Mount Sinai, New York, USA, Huazhong University of Science and Technology, China, Chinese Academy of Medical Sciences - Peking Union Medical College, China, Johns Hopkins Bloomberg School of Public Health, USA, Tongji Medical College, China, and University of Oxford, U.K. (Table 7). The thickness of the lines joining

Table 7: Scientometric profile of top 20 most productive organizations in research on "Use of Convalescent Plasma Therapy for COVID-19."

\begin{tabular}{|c|c|c|c|c|c|c|c|c|c|}
\hline S.No & Name of the Organization & TP & TC & CPP & $\mathrm{HI}$ & ICP & ICP (\%) & $\mathrm{RCI}$ & $\mathrm{TCL}$ \\
\hline 1 & Icahn School of Medicine at Mount Sinai, New York, USA & 21 & 95 & 4.52 & 4 & 4 & 19.05 & 0.35 & 80 \\
\hline 2 & Huazhong University of Science and Technology, China & 18 & 1117 & 62.06 & 6 & 9 & 50.00 & 4.78 & 181 \\
\hline 4 & Johns Hopkins Bloomberg School of Public Health, USA & 18 & 319 & 17.72 & 5 & 1 & 5.56 & 1.37 & 186 \\
\hline 5 & Tongji Medical College, China & 17 & 1116 & 65.65 & 7 & 3 & 17.65 & 5.06 & 175 \\
\hline 7 & Harvard Medical School, USA & 11 & 26 & 21.45 & 5 & 5 & 45.45 & 1.65 & 118 \\
\hline 8 & Weill Medical College, Cornell University, USA & 11 & 170 & 15.45 & 6 & 3 & 27.27 & 1.19 & 108 \\
\hline 9 & NHS Blood and Transplant, U.K. & 11 & 38 & 3.45 & 4 & 7 & 63.64 & 0.27 & 123 \\
\hline 10 & Johns Hopkins School of Medicine, USA & 10 & 196 & 19.60 & 4 & 3 & 30.00 & 1.51 & 180 \\
\hline 14 & National University of Singapore & 9 & 1786 & 198.44 & 7 & 7 & 77.78 & 15.29 & 101 \\
\hline 15 & Tehran University of Medical Sciences, Iran & 9 & 95 & 10.56 & 3 & 5 & 55.56 & 0.81 & 51 \\
\hline 16 & Massachusetts General Hospital, USA & 9 & 119 & 13.22 & 6 & 5 & 55.56 & 1.02 & 68 \\
\hline 17 & McMaster University, Canada & 9 & 118 & 13.11 & 4 & 6 & 66.67 & 1.01 & 136 \\
\hline 18 & Zhongnan Hospital of Wuhan University, China & 9 & 147 & 16.33 & 4 & 4 & 44.44 & 1.26 & 131 \\
\hline 19 & University of Cape Town, South Africa & 8 & 10 & 1.25 & 2 & 4 & 50.00 & 0.10 & 71 \\
\hline 20 & Mayo Clinic, USA & 8 & 134 & 16.75 & 4 & 2 & 25.00 & 1.29 & 54 \\
\hline 21 & University of Pennsylvania, USA & 8 & 213 & 26.63 & 5 & 4 & 50.00 & 2.05 & 74 \\
\hline 22 & Shahid Beheshti University of Medical Sciences, Iran & 8 & 28 & 3.50 & 2 & 5 & 62.50 & 0.27 & 41 \\
\hline
\end{tabular}

${ }^{*} \mathrm{TP}=$ Total publications; $\mathrm{TC}=$ Total citations; $\mathrm{CPP}=$ Citations per paper; $\mathrm{HI}=$ Herch Index; International Collaborative Papers: RCI = Relative Citation Index 
the two organizations depict the degree of collaboration between. The thicker the lines, the greater is the number of linkages between them. The top three organizations Huazhong University of Science and Technology, China, Tongji Medical College, China and Peking Union Medical College, China account for the most collaborative linkages (35, 30 and 21). Whereas organizations like INSERM, France, Shahid Beheshti University of Medical Sciences, Iran and Tehran University of

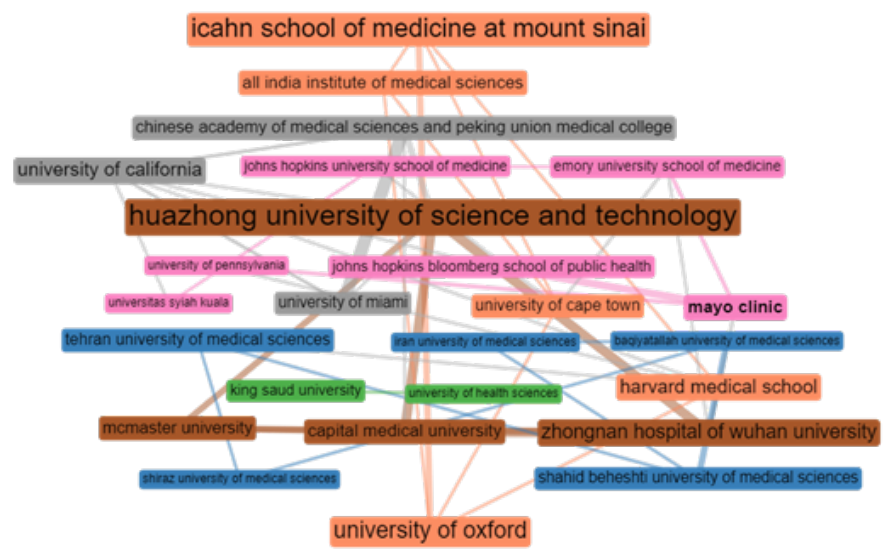

Figure 4: Collaboration Network Map of Top 25 Organizations.
Medical Sciences, Iran for the least number of collaborative linkages (1, 1 and 2). (Table 8)

\section{Most Productive Authors}

In all, 570 authors were found to have unevenly participated in global in research on "Use of Convalescent Plasma Therapy for COVID-19". The research productivity of top 25 most productive authors varied from 3 to 5 publications per author whereas global average productivity of all authors was 1.43 per author. Author-wise distribution of global research output is skewed. For example, top 25 authors together they contributed a $12.32 \%$ (101) global publications share and $10.06 \%$ (1070) global citations share. Besides, 410 authors out of 570 published 1 papers each, 94 authors 2 papers each, 45 authors 3 papers each, 14 authors 4 papers each and 7 authors 5 papers each. The detailed scientometric profile of top 25 most productive authors is presented in Table 9.

Of the top 25 authors, 10 were from USA, 3 from Turkey, 2 each from China, Greece, Iran and Italy, and 1 each from Belgium, Canada, India and U.K. On further analysis, it was observed that six authors have made contribution above the group-25 average productivity (4.04): M.A. Erkurt, Turkey, H. Harvala, U.K., M.J. Joyner, USA, F. Kramme, USA and Z. Liu, China (5 papers each); and Six authors have registered citation per paper and relative citation index higher than the group average (10.59 and 0.82): Y. Wu, China (57.75 and 4.45), Z. Liu, China (47.2 and

Table 8: Collaborative Linkages among Top 25 Organizations in research on “Use of Convalescent Plasma Therapy in COVID-19 Patents.”

\begin{tabular}{|c|c|c|c|}
\hline S.No & Name of Organization & Number of Collaborative Linkages with Different Organizations & TCL (NO) \\
\hline 1 & $\begin{array}{c}\text { Icahn School of Medicine at Mount Sinai, New York, } \\
\text { USA }\end{array}$ & $6(2), 7(1), 11(1), 19(1), 16(1), 14(1)$ & $7(6)$ \\
\hline 2 & Huazhong University of Science and Technology, China & $3(6), 5(17), 17(2), 18(4), 23(6)$ & $35(5)$ \\
\hline 3 & $\begin{array}{c}\text { Peking Union Medical College, Chinese Academy of } \\
\text { Medical Sciences, China }\end{array}$ & $2(6), 5(6), 17(2), 18(3), 23(4)$ & $21(5)$ \\
\hline 4 & John Hopkins Bloomberg School of Public Health, USA & $10(1), 20(3)$ & $4(2)$ \\
\hline 6 & University of Oxford, U.K. & $1(2), 7(1), 9(9), 10(1), 11(1), 14(1), 19(2), 25(1)$ & $18(8)$ \\
\hline 7 & Harvard Medical School, USA & $1(1), 2(1), 5(1), 6(1), 10(1), 14(1), 15(1), 16(3), 18(1), 21(1), 23(1)$ & $13(11)$ \\
\hline 8 & Sanford Weill Medical College, Cornell University, USA & $20(1), 21(3)$ & $4(2)$ \\
\hline 9 & NHS Blood and Transplant, U.K. & 6(9), 10(1), 13(1), 19(1), 22(1), 24(1), 25(1) & $15(7)$ \\
\hline 10 & John Hopkins School of Medicine, USA & $6(1), 7(1), 19(1), 24(1), 25(1)$ & $5(5)$ \\
\hline 14 & National University of Singapore & $1(1), 2(1), 6(1), 18(2), 19(1), 24(1)$ & $7(6)$ \\
\hline 15 & Tehran University of Medical Sciences, Iran & $16(1), 22(1)$ & $2(2)$ \\
\hline 16 & Massachusetts General Hospital, USA & $6(2), 7(3), 8(1) 9(2)$ & $8(4)$ \\
\hline 17 & McMasters University, Canada & $2(2), 3(2), 5(2), 23(2), 25(1)$ & $9(5)$ \\
\hline 18 & Zhongnan Hospital of Wuhan University, China & 2(4), 5(4), 7(1), !4(2), 23(4),24(1) & $17(6)$ \\
\hline 19 & University of Cape Town, South Africa & $1(1), 6(2), 9(1), 11(1), 14(1)$ & $6(5)$ \\
\hline 20 & Mayo Clinic. USA & $4(3), 14(1), 16(1), 21(1), 24(1)$ & $7(5)$ \\
\hline 21 & University of Pennsylvania, USA & $6(1), 7(1), 8(3)$ & $5(3)$ \\
\hline 22 & Shahid Beheshti University of Medical Sciences, Iran & $9(1)$ & $1(1)$ \\
\hline
\end{tabular}

$\mathrm{TCL}=$ Total Collaborative Linkages, $\mathrm{NO}=$ Number of Organizations 
Table 9: Scientometric profile of top 25 Most Productive authors in research on “Use of Convalescent Plasma Therapy for COVID-19."

\begin{tabular}{|c|c|c|c|c|c|c|c|c|c|c|}
\hline S.No & $\begin{array}{l}\text { Name of the } \\
\text { Organization }\end{array}$ & Affiliation & TP & TC & CPP & $\mathrm{HI}$ & ICP & ICP (\%) & $\mathrm{RCI}$ & TCL \\
\hline 1 & M.A. Erkurt & $\begin{array}{c}\text { Inonu University, Turgut Ozal Medical } \\
\text { Center, Malatya, Turkey }\end{array}$ & 5 & 15 & 3.00 & 3 & 2 & 40.00 & 0.23 & 38 \\
\hline 2 & H. Harvala & NHS Blood and Transfusion, U.K. & 5 & 2 & 0.40 & 1 & 3 & 60.00 & 0.03 & 84 \\
\hline 3 & M.J. Joyner & Mayp Clinic, USA & 5 & 107 & 21.4 & 3 & 0 & 0.00 & 1.65 & 62 \\
\hline 5 & Z. Liu & $\begin{array}{c}\text { Peking Union Medical College, CAMS, } \\
\text { China }\end{array}$ & 5 & 236 & 47.2 & 4 & 4 & 80.00 & 3.64 & 63 \\
\hline 6 & B.H. Shaz & New York Blood Center, USA & 5 & 6 & 1.20 & 1 & 0 & 0.00 & 0.09 & 58 \\
\hline 7 & J.A. Aberg & $\begin{array}{l}\text { ICAHN School of Medicine at Mount } \\
\text { Sinai, USA }\end{array}$ & 4 & 3 & 0.75 & 1 & 0 & 0.00 & 0.06 & 58 \\
\hline 10 & A.C. Cardevall & $\begin{array}{l}\text { John Hopkins, Bloomberg School of } \\
\text { Public Health, USA }\end{array}$ & 4 & 106 & 26.5 & 3 & 0 & 0.00 & 2.04 & 46 \\
\hline 11 & M.S. Dal & $\begin{array}{l}\text { Ankara Oncology Education and } \\
\text { Research Hospital, Ankara, Turkey }\end{array}$ & 4 & 10 & 2.5 & 2 & 2 & 50.00 & 0.19 & 46 \\
\hline 12 & K. Dhama & $\begin{array}{c}\text { Indian Veterinary Research Institute, } \\
\text { Bareilly, India }\end{array}$ & 4 & 39 & 9.75 & 2 & 3 & 75.00 & 0.75 & 23 \\
\hline 13 & M. Franchino & Azienda Ospedaliera Carlo Poma, Italy & 4 & 16 & 4.00 & 3 & 0 & 0.00 & 0.31 & 20 \\
\hline 14 & S. Korkmaz & $\begin{array}{l}\text { Ankara Oncology Education and } \\
\text { Research Hospital, Turkey }\end{array}$ & 4 & 10 & 2.50 & 2 & 2 & 50.00 & 0.19 & 43 \\
\hline 19 & E. Terpos & $\begin{array}{c}\text { National Kapodistrian University of } \\
\text { Athens, Greece }\end{array}$ & 4 & 25 & 6.25 & 2 & 3 & 75.00 & 0.48 & 68 \\
\hline 20 & Y. Wu & $\begin{array}{c}\text { Key Lab of Transfusion Adverse } \\
\text { Reactions, China }\end{array}$ & 4 & 231 & 57.75 & 4 & 4 & 100.00 & 4.45 & 75 \\
\hline 21 & H. Abolghasemi & $\begin{array}{l}\text { Baqiyatallah University of Medical } \\
\text { Sciences, Iran }\end{array}$ & 3 & 18 & 6.00 & 2 & 1 & 33.33 & 0.46 & 36 \\
\hline 22 & A. Abrams-Downey & $\begin{array}{l}\text { ICAHN School of Medicine at Mount } \\
\text { Sinai, USA }\end{array}$ & 3 & 4 & 1.33 & 2 & 0 & 0.00 & 0.10 & 76 \\
\hline 23 & R. Attou & $\begin{array}{c}\text { Centre Hospitalier University Brugmann, } \\
\text { Brussels, Belgium }\end{array}$ & 3 & 2 & 0.67 & 1 & 1 & 33.33 & 0.05 & 18 \\
\hline 24 & I. Baine & $\begin{array}{l}\text { ICAHN School of Medicine at Mount } \\
\text { Sinai, USA }\end{array}$ & 3 & 5 & 1.67 & 2 & 2 & 66.67 & 0.13 & 80 \\
\hline \multirow[t]{4}{*}{25} & F. Baldanti & Univ. degli studi di Pavia, Italy & 3 & 18 & 6.00 & 3 & 1 & 33.33 & 0.46 & 21 \\
\hline & & Total of 25 authors & 101 & 1070 & 10.59 & 2.2 & 35 & 34.65 & 0.82 & 1297 \\
\hline & & Global output & 820 & 10641 & 12.98 & & & & & \\
\hline & & Share of 25 authors in global output & 12.32 & 10.06 & & & & & & \\
\hline
\end{tabular}

${ }^{*} \mathrm{TP}=$ Total publications; $\mathrm{TC}=$ Total citations; $\mathrm{CPP}=$ Citations per paper; $\mathrm{HI}=$ Herch Index; International Collaborative Papers: $\mathrm{RCI}=\mathrm{Relative} \mathrm{Citation} \mathrm{Index}$ 
3.64), A.C. Cardevall, USA (26.5 and 2.04), N. Razaei, Iran (22.75 and 1.75), M.J.. Joyner, USA (21.4 AND 1.65) and F. Krammer, USA (11.4 and 0.88$)$.

\section{Collaborative Linkages among Top authors}

The networks collaboration map of top 16 authors (Figure 5) depicts authors in 12 clusters. Of these, 6 clusters have the most publications. Cluster 1 in red colour is formed by authors such as Aberg J.A., AbramsDowney A., Baine I., Krammer F., Liu S.T.H. and Rahman F. Cluster 2 in green colour includes authors such as Bloch E.M., Casadevall A., Joyner M.J. and Shaz B.H. Clusters 4, 5 and 6 in yellow, purple and turquoise colors have two authors each. Clusters 7 to 12 have one author each. The thickness of lines between authors depict the degree of their collaboration in research. The top three authors with largest collaborative linkages (18, 15 and 14) are A.Aberg, F.Rahman and S.T.H.Liu. The authors with least collaborative linkages $(1,2,14)$ are A.C.Casedevalli, M.Franchino and E.M.Bloch. Individual-individual author collaborations are by Z.Liu - Y.Wu, J.A.Aberg - M.S. Dal, J.A.Aberg - S.T.H.Liu, and J.A.Aberg -F.Rahman (4 linkages each) (Table 10).

\subsection{Medium of Research Communication}

All of the research publications on "Use of Convalescent Plasma Therapy for COVID-19", have appeared in journal medium. Of the total 470 journals which reported 820 articles, 331 published 1 paper each, 80 published 2 papers each, 47 published 3-5 papers each, 13 published 6-10 papers each, and 6 published 11-29 papers each.

A co-citation networks map of top 25 most productive journals (Figure 6) depicts journals in 11 clusters. In the map, two or more journals that cover closely related topics are placed close to one another, and those covering fundamentally different topics are located far from each other. The circle size and font size of a journal node is proportional to the frequency of its co-citations. Cluster 1 in red colour has 5 journals i.e. ( a-JAMA-Journal of the American Medical Association, b-Frontiers in Pharmacology, c-International Journal of Infectious Diseases, d-Journal of Infectious Diseases and e-Mayo Clinic Proceedings), Cluster 2 in green colour has 4 journals (a-Journal of Medical Virology, b-Frontiers in Medicine, c-European Journal of Pharmacology and d-Military Medical Research) and Clusters 3, 4 and 5 are in blue, yellow and purple colour with 3 journals each.

The top 25 most productive journals published 4 to 29 papers each. Together these 25 journals accounted for a $26.59 \%$ share. The top 5 most productive journals are Transfusion and Apheresis Science (29 papers), Transfusion (21 papers), JAMA-Journal of the American Medical Association (15 papers), Journal of Medical Virology (13 papers) and Frontiers in Immunology (11 papers). The top 5 most impactful journals in terms of citations per paper registered are: Military Medical Research (211.4), Nature Reviews Immunology (132.0), Journal of Medical Virology
(60.08), JAMA-Journal of the American Medical Association (42.2 and Critical Care (16.83) (Table 11).

\section{Highly Cited Papers}

Of the total output in the research on "Use of Convalescent Plasma Therapy for COVID-19" (820 publications), only 16 publications (1.95\% share)

\begin{tabular}{|c|c|c|c|}
\hline S.No & $\begin{array}{l}\text { Name of the } \\
\text { Author }\end{array}$ & $\begin{array}{l}\text { Number of collaborative } \\
\text { linkages with other authors }\end{array}$ & TCL(NOA) \\
\hline 1 & M.A. Erkurt & $11(4), 14(4)$ & $8(2)$ \\
\hline 2 & H. Harvala & Nil & Nil \\
\hline 3 & M.J. Joyner & Nil & Nil \\
\hline 4 & F. Krammer & $\begin{array}{c}6(1), 7(2), 15(2), 17(2), 22(2) \\
24(3)\end{array}$ & $12(6)$ \\
\hline 5 & Z. Liu & $20(4)$ & $4(1)$ \\
\hline 6 & B.H. Shaz & $4(1), 8(1), 17(1), 22(2), 24(1)$ & $6(5)$ \\
\hline 7 & J.A. Aberg & $\begin{array}{c}4(2), 11(4), 15(4), 17(4), 22(2), \\
24(2)\end{array}$ & $18(6)$ \\
\hline 8 & E.M. Bloch & $6(1), 10(1)$ & $2(2)$ \\
\hline 9 & P. Begin & Nil & Nil \\
\hline 10 & A.C. Casedevalli & $8(1)$ & $1(1)$ \\
\hline 11 & M.S. Dal & $1(4), 14(4)$ & $8(2)$ \\
\hline 12 & K. Dhama & Nil & Nil \\
\hline 13 & M. Franchino & $15(2)$ & $2(1)$ \\
\hline 14 & S. Korkmaz & $1(4), 11(4)$ & $8(2)$ \\
\hline 15 & S.T.H. Liu & $4(2), 7(4), 17(4), 22(2), 24(2)$ & $14(5)$ \\
\hline 16 & $\begin{array}{l}\text { I. Ntanasis- } \\
\text { Stathopoulos }\end{array}$ & $19(4)$ & $4(1)$ \\
\hline 17 & F. Rahman & $4(2), 6(1), 7(4), 15(4), 22(2), 24(2)$ & $15(6)$ \\
\hline 18 & N. Razaei & Nil & Nil \\
\hline 19 & E. Terpos & $16(4)$ & $4(1)$ \\
\hline 20 & Y. Wu & $5(4)$ & $4(1)$ \\
\hline 21 & H. Abolghasemi & Nil & Nil \\
\hline 22 & A. Abrams-Downey & $4(2), 6(2), 7(2), 17(2), 25(2)$ & $10(5)$ \\
\hline 23 & R. Attou & Nil & Nil \\
\hline 24 & I. Baine & $4(3), 7(2), 15(2), 17(2), 22(2)$ & $11(5)$ \\
\hline 25 & F. Baldanti & $13(2)$ & $2(1)$ \\
\hline
\end{tabular}

$\mathrm{TCL}=$ Total Collaborative Linkages, NOA=Number of Authors

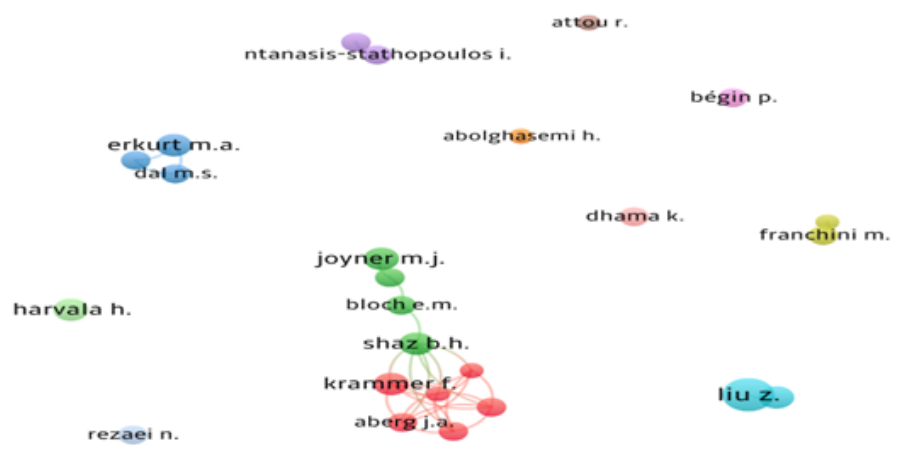

Figure 5: Collaborative Networks map of Top 16 Authors.

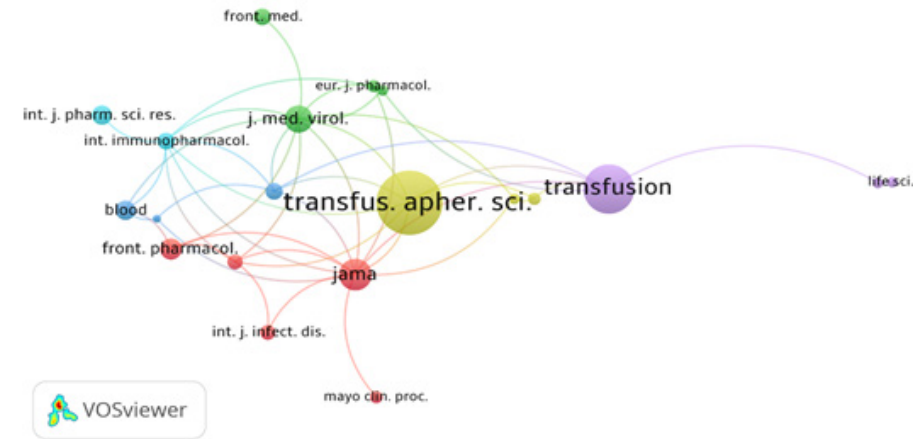

Figure 6: Co-citations Networks Map of Top 25 most productive journals. 
accumulated high citations, 101 to 977 citations per paper since their publication during 2020-21, and averaging their performance to 394.81 citations per paper (cumulative total 6317 citations). The distribution of 16 highly cited papers is skewed: 6 papers received citations in the range 101-200 per paper, 5 papers were in the citation range 201-400, 4 papers in the citations range 401-607 and 1 paper received a high of 977 citations. Of the 16 highly cited papers, 7 were published as articles, 8 as review papers and 1 as a note. Of the 16 highly cited papers, 4 were contributed by one single organization per paper (as non-collaborative papers) and the remaining 12 resulted by two or multiple organizations per paper ( 9 appeared as national collaborative and 3 as international collaborative papers). The 16 highly cited papers involved 156 authors from 83 organizations. Tongji Medical College, China contributed 3 highly cited papers, the largest number of papers, followed by National University of Singapore, Renmin Hospital of Wuhan University (2 papers

Table 11: Top 25 Most Productive Journals in research on "Use of Convalescent Plasma Therapy for COVID-19."

\begin{tabular}{|c|c|c|c|c|}
\hline & & TP & TC & CPP \\
\hline 1 & Transfusion and Apheresis Science & 29 & 93 & 3.21 \\
\hline 2 & Transfusion & 21 & 56 & 2.67 \\
\hline 3 & $\begin{array}{l}\text { JAMA-Journal of the American } \\
\text { Medical Association }\end{array}$ & 15 & 633 & 42.20 \\
\hline 4 & Journal of Medical Virology & 13 & 781 & 60.08 \\
\hline 5 & Frontiers in Immunology & 11 & 35 & 3.18 \\
\hline 6 & Frontiers in Pharmacology & 10 & 27 & 2.70 \\
\hline 7 & Blood & 9 & 72 & 8.00 \\
\hline 8 & $\begin{array}{l}\text { International Journal of Research in } \\
\text { Pharmaceutical Science }\end{array}$ & 9 & 4 & 0.44 \\
\hline 9 & Frontiers in Medicine & 8 & 6 & 0.75 \\
\hline 10 & $\begin{array}{c}\text { International } \\
\text { Immunopharmacology }\end{array}$ & 8 & 106 & 13.25 \\
\hline 11 & Vox Sanguinis & 8 & 81 & 10.13 \\
\hline 12 & $\begin{array}{c}\text { International Journal of Infectious } \\
\text { Diseases }\end{array}$ & 7 & 11 & 1.57 \\
\hline 13 & Journal of Infectious Diseases & 7 & 91 & 13.00 \\
\hline 14 & Critical Care & 6 & 101 & 16.83 \\
\hline 15 & European Journal of Pharmacology & 6 & 16 & 2.67 \\
\hline 16 & Mayo Clinic Proceedings & 6 & 4 & 0.67 \\
\hline 17 & Science & 6 & 58 & 9.67 \\
\hline 18 & Trials & 6 & 13 & 2.17 \\
\hline 19 & British Journal of Haematology & 5 & 49 & 9.80 \\
\hline 20 & $\begin{array}{l}\text { Journal of Infection and Public } \\
\text { Health }\end{array}$ & 5 & 23 & 4.60 \\
\hline 21 & Life Sciences & 5 & 63 & 12.60 \\
\hline 22 & Military Medical Research & 5 & 1057 & 211.40 \\
\hline 23 & Nature Reviews Immunology & 5 & 660 & 132.00 \\
\hline 24 & American Journal of Case Reports & 4 & 1 & 0.25 \\
\hline \multirow[t]{4}{*}{25} & BMJ & 4 & 25 & 6.25 \\
\hline & Total of 25 journals & 218 & 4066 & 18.65 \\
\hline & Global total in journals & 820 & 10641 & 12.98 \\
\hline & $\begin{array}{c}\text { Share of top } 12 \text { journals in global } \\
\text { total }\end{array}$ & 26.59 & 38.21 & \\
\hline
\end{tabular}

$\mathrm{TP}=$ Total Publications $\mathrm{TC}=$ Total Citations, $\mathrm{CPP}=$ Citations per Paper each), etc. These 16 highly cited papers appeared across 11 journals, of which 3 papers appeared in Journal of Medical Virology, 2 papers each appeared in International Journal of Microbial Agents and Journal of the JAMA-Journal of the American Medical Association and 1 paper each in Clinical Immunology, Indian Journal of Pediatrics, Journal of Korean Medical Science, Journal of Microbial Immunology and Infection, The Journal of Infectious Diseases, Military Medical Research, Nature Review Immunology, Proceedings of the NSA of USA and Translational Pediatrics.

\section{SUMMARY AND CONCLUSION}

This study evaluates global research on "Use of Convalescent Plasma Therapy for COVID-19 with the aim to describe research productivity, performance, and bibliometric mapping in the subject on bibliometric indicators. The data for the study was sourced from Scopus database covering the period 2020-2021. The global research on "Use of Convalescent Plasma Therapy for COVID-19 comprised a total of 820 publications, and these were contributed by 570 authors from 457 research organizations spread across 90 countries. The average research productivity in the subject was 1.43 per contributing author, and 1.79 per research organization. The global research output (820 publications) received a total of 10641 citations since publication. The average performance in the subject was 16.74 citations per paper for global research, and 25.39 citations per paper for the sponsored research. Only $1.95 \%$ ( 16 publications) share of 820 reported high citations above 100, between 101 and 977 citations per paper. The USA topped in the global ranking of most productive countries with a $34.88 \%$ global publication share, followed by China and India (15.98\% and $12.68 \%$ ), and 12 other most productive countries. Country-wise analysis of top 15 most productive countries reveal that only three countries - China, UK, and Netherlands had registered their citation performance above the group-15 average (14.33 CPP and 1.10 RCI). Furthermore, the study provides a window to key countries, key organizations, key authors, key source journals, popular areas of research interest, and significant keywords.

The USA, China, India have provided leadership in research studies on "Use of Convalescent Plasma Therapy for COVID-19 as most productive countries. But at the institutional level and the individual author level the picture about country performance in terms of research productivity is different. At institutional level, the USA is the home country to five out of top 10 global institutions. China to three, and the UK to two institutions. India is the home country to one institution but ranked at $11^{\text {th }}$ position. At the individual author level, it is the USA which dominates as the home country to six out of top ten authors in the global output. Interestingly, international collaboration in convalescent plasma research is seen as the strongest among the USA, China, India vis-a-vis other top 12 countries.

\section{CONFLICT OF INTEREST}

The authors declare that there is no conflict of interest.

\section{REFERENCES}

1. WHO. Coronavirus disease (COVID-19) pandemic. 2019. https:// www.who.int/emergencies/ diseases/novel-coronavirus- 2019?gclid =EAlalQobChMI39af0p307gIVkjArCh1SXw_cEAAYASAAEgJY1_D_BwE

2. COVID-19 and Convalescent Plasma and Antibody Therapies: Frequently Asked Questions. 2021. (Version 6.1; last updated January 22, 2021). https://www. hematology.org/covid-19/covid-19-and-convalescent-plasma

3. Marano G, Vaglio S, Pupella S, et al. Convalescent plasma: New evidence for an old therapeutic tool?. Blood Transfuse. 2016;14(2):152-7. doi:10.2450/2015.013115

4. Selvi V. Convalescent Plasma: A Challenging Tool to Treat COVID-19 Patients-A Lesson from the Past and New Perspectives. Biomed Res Int. 2020;2606058. Published 2020 Sep 22. doi:10.1155/2020/2606058 
5. WHO Blood Regulators Network (BRN). Position Paper on Use of Convalescent Plasma, Serum or Immune Globulin Concentrates as an Element in Response to an Emerging Virus. 2017.https://www.who.int/bloodproducts/brn/2017_BRN_ PositionPaper_ConvalescentPlasma.pdf

6. Zyoud SH, Al-Jabi SW. Mapping the situation of research on coronavirus disease-19 (COVID-19): A preliminary bibliometric analysis during the early stage of the outbreak. BMC Infect Dis. 2020;20(1):561. https://doi.org/10.1186/ s12879-020-05293-z
7. Philip S. Scientific publications and COVID-19 "research pivots" during the pandemic: An initial bibliometric analysis. BioRxiv. 2020. preprint doi: https:// doi.org/10.1101/2020.12.06.413682

8. Yue G, et al. Early Research on COVID-19: A Bibliometric Analysis. The Innovation. 2020;1(2):100027

9. Lou CJ, Tian SJ, Niu SM, Kang XQ, Lian HX, Zhang LX, et al. Coronavirus disease 2019: A bibliometric analysis and review. Eur Rev Med Pharmacol Sci. 2020;24(6):3411-21. DOI: 10.26355/eurrev_202003 20712eferences-X-

Cite this article : Gupta BM, Dhawan SM, Ahmed KKM, Mamdapur GM. Use of Convalescent Plasma Therapy for COVID-19": A Scientometric Assessment of Global Publications during 2020-21. Int J Med Public Health. 2021;11(2):65-75. 